\title{
I I 5 Parallel acquisition to improve temporal resolution in the rapid detection of myocardial infarction: comparison of image quality and artifacts
}

\author{
Amol A Bahekar*1, Jose Rodriguez-Palomares and Edwin $\mathrm{Wu}^{2}$
}

\begin{abstract}
Address: ${ }^{1}$ Rosalind Franklin University/Chicago Medical School, Chicago, IL, USA and ${ }^{2}$ Northwestern University, Chicago, IL, USA
\end{abstract}
* Corresponding author

from I / th Annual SCMR Scientific Sessions

Los Angeles, CA, USA. I-3 February 2008

Published: 22 October 2008

Journal of Cardiovascular Magnetic Resonance 2008, I0(Suppl I):AI6 doi:I0.II86/I532-429X-I0-SI-AI6

This abstract is available from: http://jcmr-online.com/content/I0/SI/AI6

(c) 2008 Bahekar et al; licensee BioMed Central Ltd.

\section{Introduction}

Imaging speed is of critical importance in Cardiac Magnetic Resonance (CMR) imaging especially in patients with severe cardiac disease. Parallel MR imaging uses spatial encoding inherent in phased-array radiofrequency coils to accelerate image acquisition to improve temporal resolution.

\section{Purpose}

Aim of the current study is to compare the CMR images of post-myocardial infarct (MI) patients acquired using single-shot inversion recovery, steady state free precession sequence with images acquired using parallel imaging technique (PAT).

\section{Methods}

Total 57 patients with either acute myocardial infarction $(\mathrm{n}=38)$ or chronic myocardial infarction $(\mathrm{n}=19)$ were included in the study. Delayed enhancement (DE) CMR was done using 1.5-T scanner (Sonata or Avanto, Siemens). Standard infarct images were acquired using single-shot, inversion recovery, steady state free-precession sequence. Parallel images were additionally acquired using Generalized Autocalibrating Partially Parallel Acquisition (GRAPPA) and modified Sensitivity Encoding (mSENSE) algorithms. An acceleration factor or "PAT" factor of 2 used to acquire parallel images. Images were blinded, randomized and scored for hyperenhancement visually on 17-segement model by consensus of 2 observ- ers. Image quality (graded excellent, good or poor) and the presence of artifacts were also assessed (Figure 1).

\section{Results}

Parallel techniques had an average $40 \%$ reduction in acquisition times during diastole. There was no difference between the standard images and GRAPPA images in terms of extent of infarct ( 4.84 vs. $4.77, \mathrm{P}=0.43$ ), microvascular obstruction ( 0.30 vs. $0.34, P=0.42)$, transmural infarct score $(1.18$ vs. $1.13, \mathrm{P}=0.43)$, and total infarct score ( 10.78 vs. $10.45, \mathrm{P}=0.41)$. Similarly there was no difference between the standard images and mSENSE images in terms of extent of infarct ( 4.84 vs. $4.84, \mathrm{P}=$ $0.50)$, micro-vascular obstruction $(0.30$ vs. $0.31, \mathrm{P}=$ $0.47)$, transmural infarct score ( 1.18 vs. $1.29, \mathrm{P}=0.38$ ), and total infarct score (10.78 vs. $10.81, \mathrm{P}=0.49)$. A greater number of standard and GRAPPA studies were graded excellent than mSENSE, and mSENSE had significantly greater artifacts than the others $(P<0.001)$. In patients with a heart rate $>65(\mathrm{n}=35)$, GRAPPA had greater excellent quality images $(43 \%)$ than standard $(29 \%, \mathrm{P}<0.05)$ or mSENSE $(14 \%, \mathrm{P}<0.05)$. Also image artifacts were significantly more prevalent in mSENSE $(43 \%)$ as compared to standard $(9 \%, \mathrm{P}<0.001)$ or GRAPPA $(9 \%, P<0.001)$.

\section{Conclusion}

All imaging techniques can adequately assess the size and extent of infarction. However at faster heart rates, GRAPPA performed better with less artifacts and more 


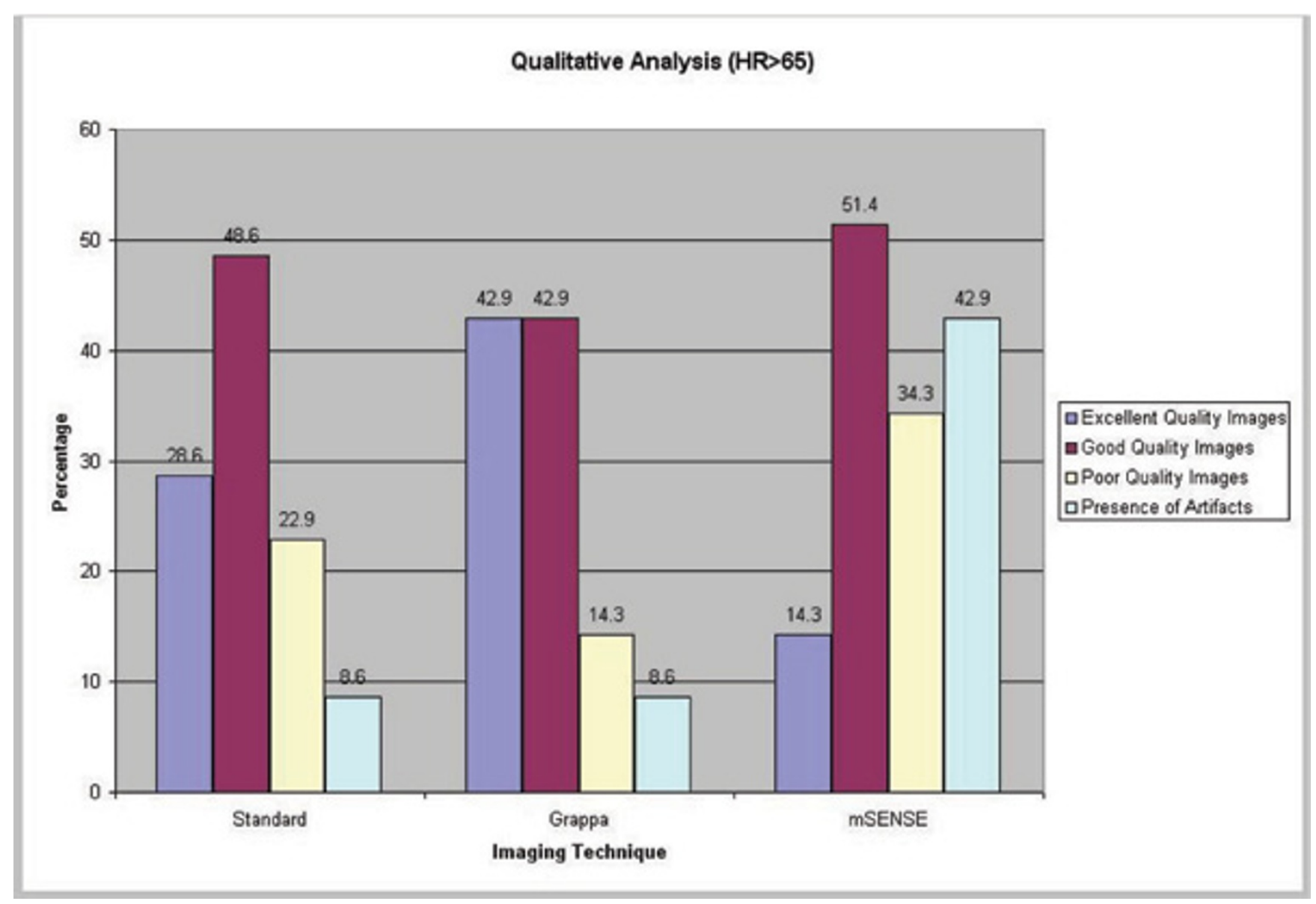

Figure I

Current study compares the conventional cardiac MRI images of post myocardial infarct patients with the images acquired using parallel imaging technique (PAT) by measuring the the size, extent of infarction and image quality.

number of excellent images than mSENSE. The high quality images with GRAPPA are due to an improvement in temporal resolution.
Publish with Biomed Central and every scientist can read your work free of charge

"BioMed Central will be the most significant development for disseminating the results of biomedical research in our lifetime. " Sir Paul Nurse, Cancer Research UK

Your research papers will be:

- available free of charge to the entire biomedical community

- peer reviewed and published immediately upon acceptance

- cited in PubMed and archived on PubMed Central

- yours - you keep the copyright
BioMedcentral 